\title{
PENGEMBANGAN APLIKASI WEB PERANCANGAN AGENDA PERJALANAN WISATA MENGGUNAKAN METODE USER EXPERIENCE LIFECYCLE
}

\author{
Ariq Cahya Wardhana*1, Nenny Anggraini², Nurul Faizah Rozy ${ }^{3}$ \\ ${ }^{1}$ Prodi S1 Rekayasa Perangkat Lunak, FIF, Institut Teknologi Telkom Purwokerto \\ ${ }^{2,3}$ Teknik Informatika, FST, Universitas Islam Negeri Syarif Hidayatullah Jakarta \\ Email: 1ariq@ittelkom-pwt.ac.id, ${ }^{2}$ nenny.anggraini@uinjkt.ac.id, ${ }^{3}$ nurul.faizah@uinjkt.ac.id \\ *Penulis Korespondensi
}

(Naskah masuk: 13 November 2019, diterima untuk diterbitkan: 22 Maret 2021)

\begin{abstract}
Abstrak
Berwisata memiliki beberapa kebutuhan sebelum melakukan perjalanan, salah satunya merancang itinerary. Itinerary merupakan rancangan jadwal perjalanan wisata yang membantu wisatawan agar lebih terarah dan teratur. Kurang lengkapnya informasi itinerary perjalanan wisata di Indonesia seperti informasi cara menuju destinasi, transportasi, beserta biayanya menyebabkan wisatawan lebih memilih keluar negeri. Selain itu, kemudahan penyusunan itinerary sangat berpengaruh pada keinginan menuju destinasi wisata. Penelitian ini bertujuan mengembangkan aplikasi berbagi pengalaman perjalanan wisata dalam bentuk itinerary berbasis web. Metode User Experience (UX) Lifecycle berhasil diterapkan pada proses pengembangan aplikasi yang dimulai dari tahap analisis untuk memahami kebutuhan pengguna melalui wawancara dan kuisioner online dengan 136 responden. Tahap desain dilakukan pembuatan persona, sketsa, storyboard, skenario dan wireframe. Hasil desain diimplementasikan dalam bentuk prototipe high fidelity berbasis web. Selanjutnya dilakukan evaluasi prototipe yang menunjukan secara keseluruhan aplikasi berhasil membantu wisatawan dalam merencanakan perjalannnya.
\end{abstract}

Kata kunci: aplikasi berbasis web, itinerary, user experience, user experience lifecycle

\section{WEB APPLICATION DEVELOPMENT FOR A TOURIST TRAVEL AGENDA USING USER EXPERIENCE LIFECYCLE METHOD}

\begin{abstract}
Traveling has several needs before traveling, one of which is designing an itinerary. The itinerary is an itinerary travel design that helps tourists to be more directed and organized. The lack of complete itinerary information on tourist trips in Indonesia, such as information on how to get to destinations, transportation, and their costs, causes tourists to prefer going abroad. Also, the ease of preparation of the itinerary is very influential in the desire to travel destinations. This study aims to develop applications for sharing travel experiences in the form of a webbased itinerary. The User Experience (UX) Lifecycle method was successfully applied to the application development process, starting from the analysis phase to understand user needs through online interviews and questionnaires with 136 respondents. The design phase is carried out, making persona, sketches, storyboards, scenarios, and wireframes - the next step to implement it in the form of a web-based high-fidelity prototype. The prototype evaluation results show that overall, the application succeeded in helping travelers planning their journey.
\end{abstract}

Keywords: itinerary, user experience, user experience lifecycle, web application

\section{PENDAHULUAN}

Perancangan agenda perjalanan atau disebut itinerary dapat membuat perjalanan traveler terencana dengan baik, budget teralokasi dengan tepat dan daftar tempat kunjungan wisata tertata dengan sempurna (Husnia 2014). Selain itu, itinerary merupakan daftar yang mengurutkan kegiatan perjalanan secara kronologis, lengkap dengan informasi pendukung seperti lokasi, jumlah hari, kegiatan, informasi akomodasi dan transportasi, serta hal-hal pendukung lainnya (Adinugroho 2010).

Dalam perjalanan wisatawan, itinerary merupakan hal yang sangat penting agar perjalanan lebih terarah dan teratur. Melalui itinerary, wisatawan akan merasa tenang selama berpergian karena semua informasi maupun akomodasi sudah diperkirakan sejak awal (Sihmanto 2010). Hal ini dipertegas dengan hasil kuisioner online yang dilakukan penulis terhadap 136 responden, 92.6\% 
responden menyatakan bahwa itinerary sangatlah penting.

Kemudahan penyusunan itinerary sangat berpengaruh pada keinginan untuk menuju destinasi wisata. Dengan mudahnya pengumpulan informasi itinerary pada suatu destinasi, memudahkan merencanakan perjalanan wisatanya. Hal ini berpengaruh terhadap motivasi wisatawan melakukan perjalanan wisata, khususnya perjalanan di Indonesia.

Salah satu cara untuk mengatasi masalah tersebut adalah membuat aplikasi yang dapat membantu wisatawan menyusun serta membagikan itinerary. Hasil kuisioner online yang disebarkan oleh penulis terhadap 136 responden sebesar 92,6\% menyatakan bahwa mereka menginginkan adanya aplikasi tersebut. Selain itu, sebesar 42,6\% mereka lebih memilih menggunakan media sosial untuk mencari informasi perjalanan wisata daripada menggunakan website official khusus yang hanya sebesar $12,5 \%$.

Sebesar 94,9\% responden menyatakan bahwa kemudahan penggunaan serta tampilan yang menarik mempengaruhi mereka dalam menggunaakan aplikasi, website atau teknologi informasi tersebut. Berdasarkan hal tersebut diperlukan sebuah metode yang memperhatikan aspek pengalaman pengguna dalam pengembangannya. Salah satu metode yang dapat digunakan untuk mengembangkan aplikasi tersebut adalah menggunakan User Experience (UX) Lifecycle.

Pada dasarnya, UX Lifecycle merupakan sebuah siklus kerangka terstruktur yang terdiri dari serangkaian tahapan seperti analisis, desain, implementasi, dan evaluasi. Metode ini membuat dan memperbaiki desain yang mengarah pada pengalaman pengguna yang berkualitas (Hartson dan Pyla 2012).

Terdapat beberapa penelitian pengembangan aplikasi menggunakan metode UX Lifecycle yaitu penelitian Nadhirah (2015) yang menfokuskan pengembangan aplikasi mobile visit puncak namun hanya sampai prototipe medium fidelity. Penelitian yang dilakukan oleh Juzma (2019) merancang desain halaman evaluasi pelatihan trainer berdasarkan pengalaman pengguna. Wardhana dan Fitriana (2021) juga melakukan penelitian terkait penerapan metode tersebut pada perancangan aplikasi tingkat kesiapan inovasi dengan metode evaluasi System Usability Scale (SUS). Sehingga, penelitian ini bertujuan menggunakan metode UX Lifecycle untuk mengembangkan aplikasi web dalam meningkatkan pengalaman wisatawan dalam mempermudah merancang itinerary.

\section{METODE PENELITIAN}

Penelitian ini menggunakan metode yang mengadaptasi User Experience Lifecycle oleh Hartson dan Pyla (2012). Kerangka pemikiran yang digunakan pada penelitian ini dapat dilihat pada Gambar 1.
Tahap pertama dilakukan proses pengumpulan data melalui wawancara dengan Dinna Mulyani selaku founder komunitas backpacker dolanyukz/travelmate dan kuisioner secara online yang dibagikan pada forum komunitas backpacker untuk memperkuat hasil wawancara. Hasil dari kedua proses tersebut dilakukan analisa untuk memperoleh rumusan masalah.

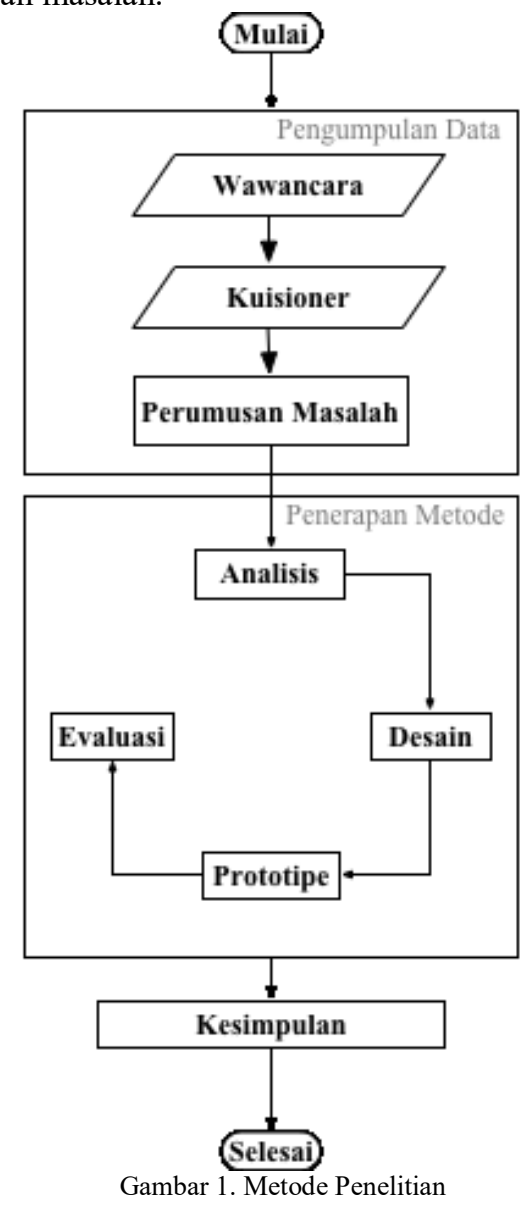

Tahap kedua yaitu penerapan metode user experience lifecycle yang terdiri dari empat proses yaitu:

1. Analisis

Pada proses ini dilakukan analisis berdasarkan hasil wawancara dan kuisioner online pada tahap sebelumnya melalui aktivitas pembuatan system concept statement, contextual inquiry, contextual analysis, extracting requirement dan design informing model.

2. Desain

Melakukan proses desain berdasarkan hasil analisis melalui pembuatan design thinking dan ideation, conceptual design dan design production.

3. Prototipe

Implementasi hasil desain yang dibuat pada tahap sebelumnya melalui pembuatan prototipe high fidelity berbasis web menggunakan bahasa pemrograman PHP dan Database MySQL. Framework yang digunakan adalah bootstrap dan codeigniter. 


\section{Evaluasi}

Evaluasi dilakukan menggunakan dibagikan secara online dengan penghitungan skala likert kepada calon pengguna aplikasi di forum komunitas wisata

\section{ANALISA DAN PEMBAHASAN}

\subsection{Agenda Perjalanan}

Agenda perjalanan atau itinerary merupakan rencana detail kunjungan atau wisata anda (Travelsingapura 2012). Biasanya berisi daftar tujuan dan waktunya. Pembuatan itinerary sangat dianjurkan agar liburan anda lebih terencana. Salah satu tips dalam pembuatan itenerary adalah realistis, artinya pertimbangkan waktunya jangan sampai terburu-buru karena mengejar banyak tempat tujuan.

Menurut Sihmanto (2010), itinerary dalam perjalanan backpacker merupakan hal yang sangat penting agar perjalanan lebih terarah dan teratur. Melalui itinerary, backpacker akan merasa tenang selama berpergian karena semua informasi maupun akomodasi sudah diperkirakan sejak awal.

Rencana perjalanan (itinerary) adalah daftar yang mengurutkan kegiatan perjalanan secara kronologis, lengkap dengan informasi pendukung seperti lokasi, jumlah hari, kegiatan, informasi akomodasi dan transportasi, serta hal-hal pendukung lainnya. Rencana perjalanan sangat penting dibuat baik untuk perjalanan pendek atau panjang (Adinugroho 2010).

\subsection{User Experience Lifecycle}

Experience atau pengalaman merupakan suatu hasil persepsi atau reaksi dari seseorang terhadap suatu produk, sistem atau jasa. User Experience (UX) mencakup emosi, keyakinan, preferensi, persepsi, respon fisik, perilaku dan pencapaian dari pengguna tersebut yang terjadi sebelum, selama dan setelah menggunakan produk/sistem. (ISO 2010)

Pengalaman pengguna atau User Experience (disingkat UX) adalah cara untuk membuat seseorang merasa nyaman ketika berinteraksi dengan sistem. Sistem ini bisa menjadi website, aplikasi web atau desktop software. Dalam konteks modern, umumnya dilambangkan dengan beberapa bentuk interaksi manusia-komputer (Chandler dan Unger 2012).

Pengalaman pengguna atau user experience (UX) adalah fokus pemahaman yang mendalam tentang pengguna, apa yang mereka butuhkan, apa yang mereka nilai, kemampuan mereka, dan juga keterbatasan mereka (Hartson dan Pyla 2012). Hal ini juga memperhitungkan tujuan bisnis maupun tujuan sebuah proyek.

Menurut Hessenzahl (2013), user experience bukan tentang desain yang baik dalam dunia industri, multi-touch, atau interface mewah. Ini adalah tentang fancy interface (menyukai sebuah tampilan), yaitu tentang menciptakan pengalaman pengguna melalui perangkat.

Selain itu, user experience (UX) dapat dikatakan efek yang dirasakan oleh pengguna sebagai hasil dari interaksi penggunaan sistem, perangkat, atau produk. Termasuk pengaruhnya terhadap kegunaan, dampak emosional selama interaksi, dan kenikmatan setelah berinteraksi. Maksud dari interaksi sangat luas serta memiliki cakupan seperti melihat, menyentuh, dan berpikir tentang sistem atau produk, termasuk mengagumi tampilan sebelum interaksi fisik (Hartson dan Pyla 2012).

User Experience (UX) Lifecycle merupakan sebuah metode yang memperhatikan pengalaman pengguna (UX) serta melibatkan beberapa tahapan dalam sebuah lifecycle. Siklus ini terdiri dari empat aktivitas utama, yaitu analisis, desain, prototipe, dan evaluasi (Hartson dan Pyla 2012).

Konsep UX Lifecycle lebih pada sebuah metode yang lebih spesifik pada pengalaman pengguna (UX). Saat dilakukan fase implementasi, fase tersebut hanya terbatas pada komponen desain interaksinya saja. Prototipe merupakan manifestasi dari desain yang dirancang sebelumnya. Lalu dilakukan evaluasi sebelum produk tersebut dirilis atau diproduksi (Hartson dan Pyla 2012).

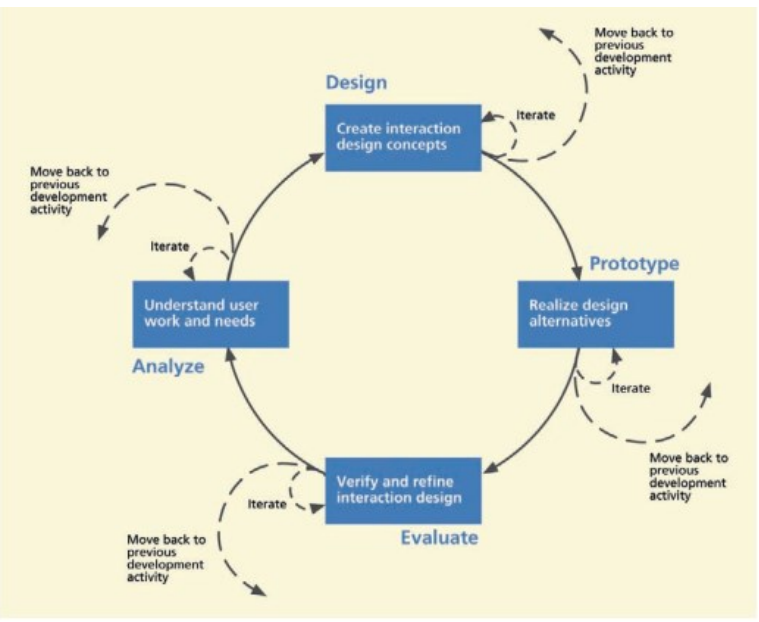

Gambar 2. User Experience Lifecycle (Hartson dan Pyla 2012)

Pada proses analisis dilakukan lima aktivitas yaitu:

1. System Concept Statement

Menurut Hartson dan Pyla (2012), system concept statement adalah ringkasan deskriptif singkat dari sistem atau produk yang menyatakan visi awal sistem. Singkatnya, itu adalah pernyataan misi untuk proyek tersebut.

\section{Contextual Inquiry}

Mengumpulkan deskripsi rinci dari kerja praktek pengguna untuk tujuan memahami kegiatan kerja dan pemikiran yang mendasarinya. Tujuan penyelidikan kontekstual adalah untuk meningkatkan praktek kerja pengguna yang membangun dan meningkatkan desain sistem untuk mendukungnya (Hartson dan Pyla 2012). 


\section{Contextual Analysis}

Identifikasi analisis sistematis, penyortiran, pengorganisasian, interpretasi, konsolidasi, dan komunikasi dari pekerjaan pengguna data aktivitas kontekstual dikumpulkan dalam contextual inquiry, untuk tujuan memahami konteks kerja sistem baru yang akan dirancang (Hartson dan Pyla 2012).

\section{Extracting Requirement}

Note aktivitas kerja pengguna dianalisis untuk menentukan apa saja yang menjadi kebutuhan desain interaksi. Statement kebutuhan interaksi desain tersebut dikemas dalam sebuah requirements document (Hartson dan Pyla 2012).

5. Design Informing Models

Abstraksi dimensi yang berbeda antara work roles dan area desain. Hal ini termasuk model yang menggambarkan bagaimana pekerjaan dilakukan, bagaimana peran berbeda dalam setiap interaksi domain work roles (Hartson dan Pyla 2012).

Tahap selanjutnya adalah proses desain yang dilakukan melalui tiga aktivitas yaitu:

1. Design Thinking and Ideation

Cara berpikir pada konsep desain sebuah produk untuk memberikan emotional impact dan pengalaman pengguna secara dominan. Dengan kata lain, design thinking adalah sebuah pendekatan untuk menciptakan produk yang membangkitkan pengalaman pengguna, mencakup dampak emosional, estetika, dan nilai interaksi sosial (Hartson dan Pyla 2012).

Ideation merupakan penggambaran ide yang aktif, kreatif, eksploratif, iterative, bergerak cepat dalam proses kolaboratif berkelompok untuk membentuk ide-ide untuk desain. Dengan fokus pada brainstorming, ideation menerapkan design thinking (Hartson dan Pyla 2012).

2. Conceptual Design

Bagian dari desain interaksi yang mengandung tema, gagasan, atau ide dengan tujuan berkomunikasi melalui visi desain sistem atau produk. Conceptual design juga merupakan manifestasi dari model mental desainer dalam sistem (Hartson dan Pyla 2012).

3. Design Production

Produksi desain memerlukan prototyping dan iterasi dari desain konseptual. Sehingga dapat dikatakan bahwa design production merupakan tahap ekstraksi desain menjadi sebuah interaksi interface sebelum produk itu masuk ke tahap selanjutnya (Hartson dan Pyla 2012).

Tahap selanjutnya adalah proses pembuatan prototipe yang dapat dilakukan melalui beberapa aktivitas. Salah satunya adalah high fidelity prototipe yaitu representasi lebih rinci dari desain, termasuk rincian tampilan dan perilaku interaksi. Prototipe ini memerlukan evaluasi detail dari desain dan bagaimana pengguna dapat melihat secara lengkap desain dari produk yang ditawarkan. Prototipe ini sebagai proses menyempurnakan rincian desain untuk mendapatkan desain yang lengkap untuk menuju implementasi akhir (Hartson dan Pyla 2012).
Tahap terakhir pada metode ini yaitu melakukan proses evaluasi. Evaluasi ini dapat dilakukan melalui berbagai model. Salah satunya adalah The Quis yang dikembangkan di University of Maryland adalah salah satu yang paling awal jenis kuesioner kepuasan pengguna untuk digunakan dalam evaluasi kegunaan. Itu kuesioner yang paling luas dan paling menyeluruh divalidasi pada saat perkembangannya untuk menentukan subjektif desain interaksi (Hartson dan Pyla 2012).

\subsection{Hasil Wawancara}

Hasil wawancara dilakukan dengan Dinna Mulyani menunjukan bahwa sebelum melakukan perjalanan, wisatawan biasa melakukan pencarian tiket, menyiapkan akomodasi, persyaratan, dan membuat itinerary. Lebih menyukai wisata backpacker daripada melalui agen wisata karena lebih murah.

Pencarian informasi dilakukan melalui blog, buku, website official negara, mencari tiket promosi serta penginapan. Itinerary sangat penting karena dapat memperkirakan biaya dan keinginan menuju destinasi wisata lebih terencana. Kekurangan perjalanan wisata di Indonesia masih belum ada informasi biaya yang jelas dan tidak banyak itinerary wisata ke destinasi nasional.

Kurangnya informasi detail mengenai destinasi nasional menyebabkan memilih ke luar negeri, selain itu karena tiket promosi di Indonesia sangat jarang (lebih mahal dibandingkan ke luar negeri). Informasi wisata di Indonesia masih berbasis sosial media dan masih sebatas obrolan kebutuhan yang dicari sehingga sangat minim detail informasi.

\subsection{Hasil Kuisioner}

Kuisioner telah berhasil dibagikan pada 136 responden dengan rata-rata umur responden sebesar 25-35 tahun dan didominasi perempuan sebesar 73 responden. Responden rata-rata melakukan perjalanan wisata 1 kali dalam setahun dan lebih memilih wisata secara backpacker karena lebih murah.

Teknologi informasi yang dominan digunakan adalah sosial media, forum, dan website official khusus. Kemudahan penggunaan mempengaruhi penggunaan teknologi informasi tersebut. Sebesar $92.6 \%$ responden menyatakan itinerary sangatlah penting untuk perjalanan wisata. Sebesar 56.6\% menyatakan sistem yang membantu mencari, membuat, atau membagikan itinerary sangat dibutuhkan. Dominasi pencarian informasi itinerary bertujuan untuk mendapatkan informasi destinasi tujuan, review cerita selama perjalanan dan biaya perjalanan.

\subsection{Perumusan Masalah}

Berdasarkan hasil wawancara dan kuisioner dapat dirumuskan permasalahan utama yang 
dibutuhkan wisatawan saat akan melakukan perjalanan wisata yaitu sangat dibutuhkannya aplikasi berbagi agenda perjalanan wisata untuk membantu melakukan perencanaan.

\subsection{Analisis}

Berdasarkan hasil wawancara dan kuisoner dilakukan pembuatan system concept statement sebagai berikut:

Aplikasi berbasis web yang memberikan kemudahan bagi wisatawan untuk merencanakan perjalanan wisatanya. Pengguna dapat membagikan pengalaman perjalanan wisata dalam bentuk itinerary atau mencari informasi itinerary yang telah dibagikan pengguna lain. Pengguna harus terdaftar dahulu sebagai anggota jika ingin membuat itinerary.

Proses pembuatan itinerary dilakukan pengguna dengan memasukan informasi destinasi, transportasi, biaya, serta aktivitas selama perjalanan. Komentar juga dapat dilakukan pengguna pada itinerary yang telah dibagikan. Sharing itinerary juga dapat dilakukan pengguna ke media sosial. Pengguna dapat membaca rute transportasi serta destinasi selama perjalanan dalam bentuk timeline.

Selanjutnya dilakukan analisis contextual inquiry yang dipetakan dari hasil wawancara dan kuisioner. Hasil analisa menunjukan belum adanya aplikasi itinerary khusus perjalanan wisata di Indonesia, kesulitan melakukan perencaan wisata di Indonesia karena kurang terakomodirnya informasi cara menuju destinasi, lebih memilih wisata secara backpacker, dan media sosial merupakan sarana yang paling sering digunakan oleh wisatawan untuk mencari informasi.

Aktivitas selanjutnya adalah melakukan perancangan contextual analysis menggunakan teknik flow model untuk merepresentasikan skenario aplikasi yang dapat dilihat pada Gambar 3. Selain itu dilakukan proses pemetaan kategori dan beberapa kategori minor berdasarkan hasil kuisioner pada kolom komentar keinginan pengguna. Pada kategori [A] terbagi menjadi empat kategori minor yaitu keinginan untuk mengetahui durasi perjalanan menuju destinasi [AA], dapat memilih alternatif transportasi $[\mathrm{AB}]$, mengetahui biaya transportasi yang diperlukan $[\mathrm{AC}]$, serta dapat mengetahui gambaran rute transportasi [AD].

Sedangkan untuk mengakses informasi dengan mudah [B] wisatawan menginginkan aplikasi dapat digunakan di semua platform [BA], informasi itinerary mudah dibagikan dengan orang lain [BB], mudah dilakukan filter informasi itinerary [BC], mudah membaca pattern destinasi [BD], serta mudah bertanya kepada pengguna lain [BE].

Pada kategori [C] terbagi menjadi tujuh kategori minor antara lain keinginan untuk memperoleh informasi berupa foto destinasi [CA], memuat informasi detail biaya selama di destinasi [CB], review tentang destinasi [CC], informasi biaya masuk destinasi [CD], informasi event yang ada di destinasi
[CE], informasi akomodasi selama di destinasi [CF] yang terdiri dari informasi aktifitas selama didestinasi [CF1] serta informasi biaya yang dibutuhkan setiap aktifitas [CF2]. Wisatawan juga menginginkan adanya maps atau peta [CG] yang berisi informasi lokasi destinasi wisata [CG1].

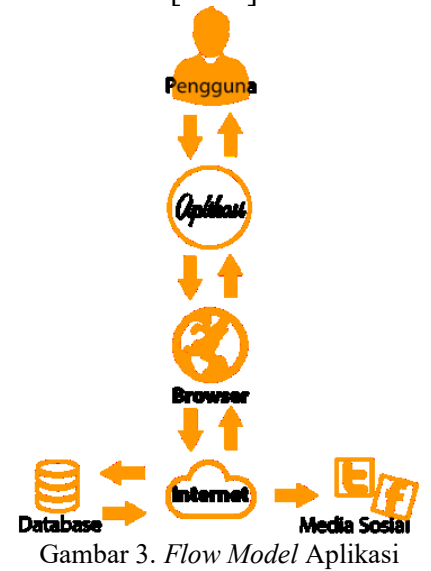

Wisatawan menginginkan adanya informasi penginapan [D] yang terdiri dari informasi biaya penginapan [DA] serta rekomendasi penginapan [DB]. Selain itu, detail biaya selama perjalan juga dibutuhkan[E] seperti informasi estimasi total biaya keseluruhan selama perjalanan [EA].

Selanjutnya, berdasarkan hasil pemetaan kategori dilakukan extracting design requirement untuk menentukan work activity yang mungkin dibuat. Hasil requirement dapat dilihat pada Tabel 1.

Tabel 1. Hasil Extracting Design Requirement

\begin{tabular}{|c|c|c|}
\hline ID & Work Activity & Feasibility \\
\hline $\mathrm{AA}$ & $\begin{array}{l}\text { Mengetahui durasi perjalanan menuju } \\
\text { destinasi }\end{array}$ & $\sqrt{ }$ \\
\hline $\mathrm{AB}$ & Memilih alternatif transportasi & $\sqrt{ }$ \\
\hline $\mathrm{AC}$ & $\begin{array}{l}\text { Mengetahui biaya transportasi yang } \\
\text { diperlukan }\end{array}$ & $\sqrt{ }$ \\
\hline $\mathrm{AD}$ & $\begin{array}{l}\text { Mengetahui gambaran rute } \\
\text { transportasi }\end{array}$ & $\sqrt{ }$ \\
\hline BA & $\begin{array}{l}\text { Aplikasi dapat digunakan di semua } \\
\text { platform }\end{array}$ & $\sqrt{ }$ \\
\hline $\mathrm{BB}$ & Mudah dibagikan dengan orang lain & $\sqrt{ }$ \\
\hline $\mathrm{BC}$ & $\begin{array}{l}\text { Mudah dilakukan filter informasi } \\
\text { itinerary }\end{array}$ & $\sqrt{ }$ \\
\hline BD & Mudah membaca pattern destinasi & $\sqrt{ }$ \\
\hline $\mathrm{BE}$ & $\begin{array}{l}\text { Mudah bertanya kepada pengguna } \\
\text { lain }\end{array}$ & $\sqrt{ }$ \\
\hline $\mathrm{CA}$ & Mendapatkan informasi foto destinasi & $\sqrt{ }$ \\
\hline $\mathrm{CB}$ & $\begin{array}{l}\text { Memuat informasi detail biaya selama } \\
\text { di destinasi }\end{array}$ & $\sqrt{ }$ \\
\hline $\mathrm{CC}$ & Melihat review tentang destinasi & $\sqrt{ }$ \\
\hline $\mathrm{CD}$ & $\begin{array}{l}\text { Mengetahui informasi biaya masuk ke } \\
\text { destinasi }\end{array}$ & $\sqrt{ }$ \\
\hline $\mathrm{CE}$ & $\begin{array}{l}\text { Mengetahui informasi event yang ada } \\
\text { di destinasi }\end{array}$ & $\mathrm{x}$ \\
\hline CF1 & $\begin{array}{l}\text { Mengetahui informasi aktifitas selama } \\
\text { di destinasi }\end{array}$ & $\sqrt{ }$ \\
\hline $\mathrm{CF} 2$ & $\begin{array}{l}\text { Informasi biaya setiap aktifitas selama } \\
\text { di destinasi }\end{array}$ & $\sqrt{ }$ \\
\hline CG1 & Informasi peta lokasi destinasi & $\mathrm{x}$ \\
\hline DA & Informasi biaya penginapan & $\mathrm{x}$ \\
\hline DB & Informasi rekomendasi penginapan & $\mathrm{x}$ \\
\hline EA & $\begin{array}{l}\text { Informasi total biaya keseluruhan } \\
\text { selama perjalanan }\end{array}$ & $\sqrt{ }$ \\
\hline
\end{tabular}


Setelah memiliki requirement document, proses selanjutnya adalah aktivitas akhir proses analisis melalui pembuatan social model untuk menggambarkan work roles serta kebutuhan interaksinya didalam sistem dapat dilihat pada Gambar 4. Work roles pada penelitian ini adalah wisatawan.

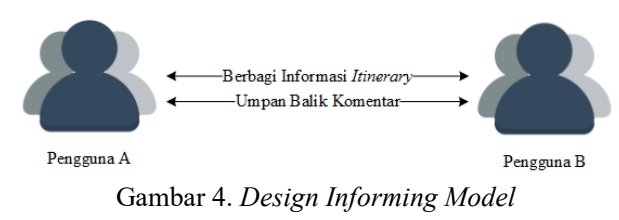

\subsection{Desain}

Hasil dari proses analisa dilakukan perancangan desain melalui tiga aktivitas. Pertama yaitu melakukan perancangan design thiking and ideation menggunakan teknik persona dan sketching. Persona merupakan gambaran mengenai profil pengguna yang sebenarnya, kebutuhan, keinginan, dan harapan untuk merancang kemungkinan pengalaman terbaik bagi wisatawan secara spesifik yang dapat dilihat pada Gambar 5.

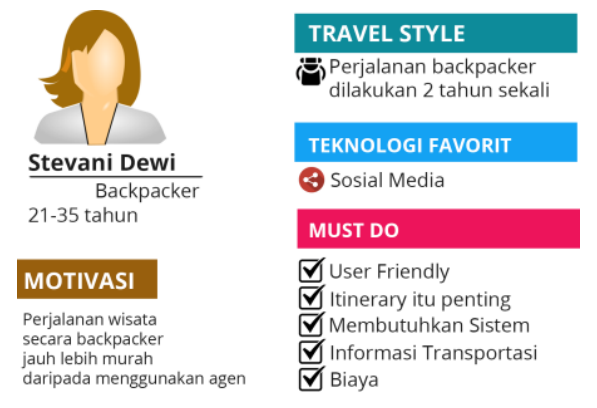

Gambar 5. Persona

Pemodelan bentuk desain timeline tersebut diterapkan pada antarmuka kumpulan aktifitas perjalanan itinerary dengan sedikit modifikasi untuk memberikan user experience yang berbeda pada pengguna, seperti pada Gambar 6 .

Kedua, dilakukan perancangan conceptual design menggunakan storyboard dan dijelaskan secara lengkap melalui skenario. Storyboard adalah konsep desain frame to frame berupa ilustrasi pengguna saat berinteraksi dengan aplikasi. Storyboard mengkombinasikan gambar dan kata-kata yang menjelaskan kegiatannya melakukan persiapan perjalanan wisatwan serta kebutuhannya terhadap aplikasi untuk mendukung kebutuhan persiapan perjalanan wisata. Storyboard dapat dilihat pada Gambar 7.

Pengguna mencari informasi itinerary lalu mengakses aplikasi menggunakan browser, diarahkan ke halaman utama. Pada halaman utama pengguna mencari informasi itinerary berdasarkan destinasi tujuan. Aplikasi akan memberikan pilihan informasi detail itinerary untuk pengguna.

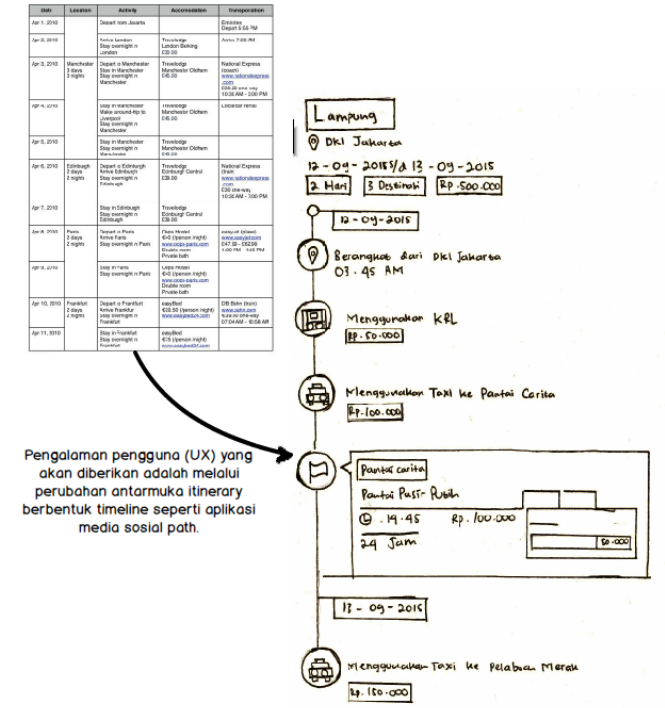

Gambar 6. Sketsa Timeline Itinerary Aplikasi

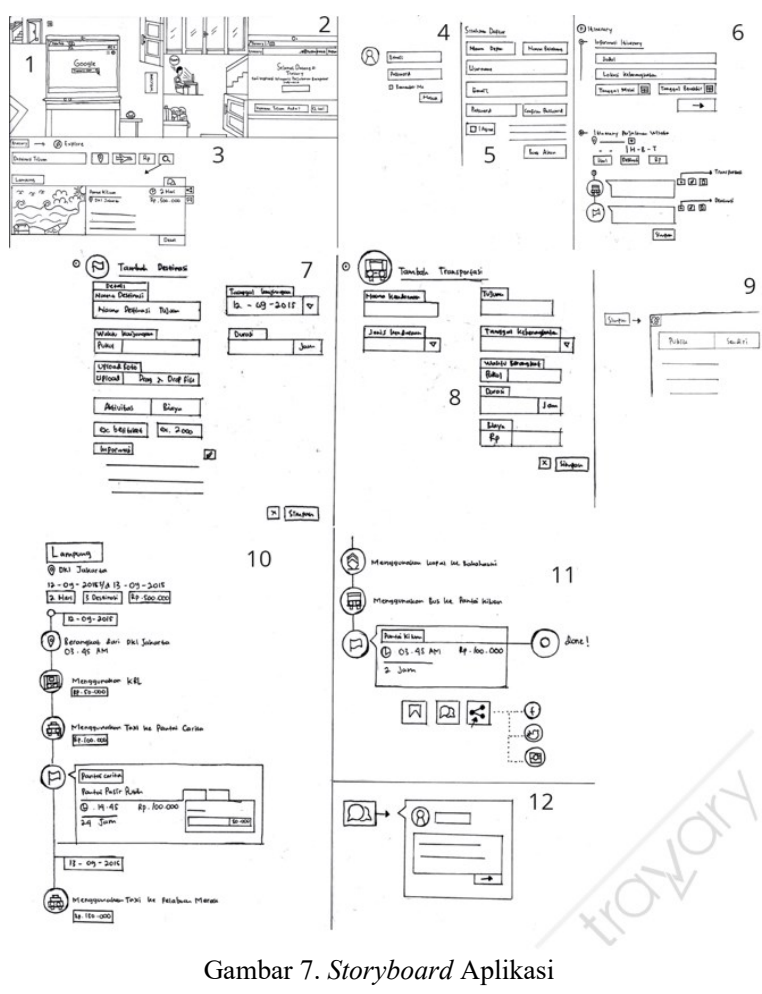

Pengguna memilih destinasi lalu diarahkan ke halaman explore yang berisi kumpulan informasi itinerary. Informasi itinerary dapat dipilih pengguna berdasarkan biaya, destinasi maupun waktu publikasi. Pengguna akan diarahkan ke halaman daftar atau masuk untuk mendapatkan informasi pada halaman detail itinerary maupun membuat itinerary.

Jika memutuskan untuk memilih itinerary yang sesuai pada halaman detail itinerary, pengguna akan mendapatkan informasi lengkap mengenai destinasi yang dipilih berdasarkan pengalaman pengguna lain yang telah dibagikan. Selain itu, pengguna juga dapat berkomentar maupun melakukan sharing diluar lingkungan aplikasi. 
Pengguna juga dapat membuat itinerary, dengan menambah informasi destinasi maupun transportasi selama perjalanan. Transportasi dapat dipilih dengan beragam alternatif pilihan beserta biayanya. Pada tambah destinasi pengguna akan memberikan pengalaman kunjungan atau informasi tentang destinasi, seperti informasi tiket masuk, akomodasi, maupun aktifitas serta biayanya. Pengaturan informasi itinerary juga dapat dilakukan pengguna dengan mengatur untuk publik atau pribadi.

Ketiga, dilakukan aktivitas design production melalui pembuatan wireframe yang menerapkan komponen desain bootstrap dari Spurlock (2013) menggunakan mockup. Langkah pertama diawali dengan membuat pattern layout utama aplikasi yang terdiri dari pattern layout browser dan pattern layout mobile. Pemanfaatan fitur responsive bootstrap diterapkan pada pembuatan pattern layout ini. Hasil design production dapat dilihat pada Gambar 8 .

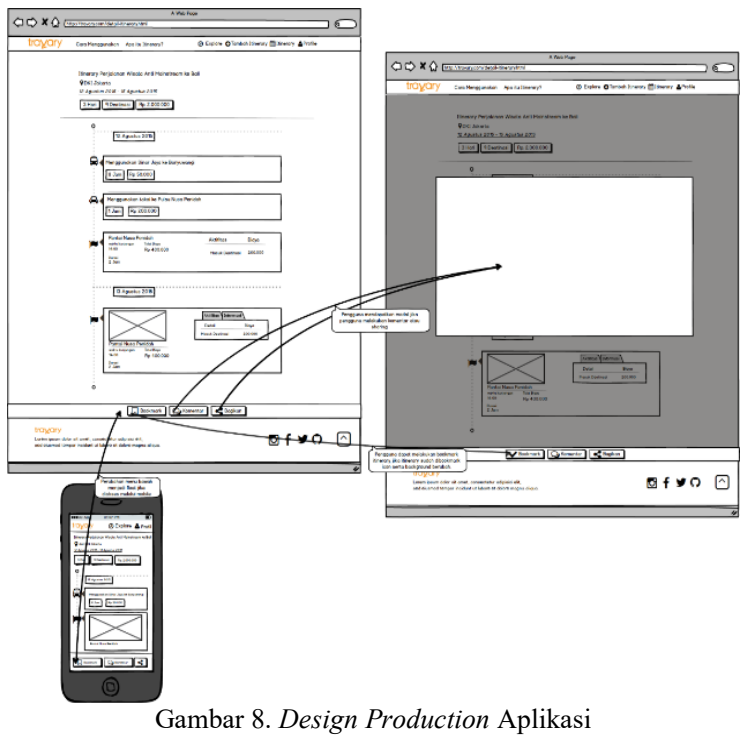

Keinginan wisatawan untuk memperoleh informasi pilihan alternatif transportasi serta rute transportasi menuju destinasi ditampilkan melalui komponen icon yang berbeda berbentuk timeline ke bawah seperti gambar diatas. Icon ditampilkan sesuai dengan jenis transportasinya.

\subsection{Prototipe}

Proses selanjutnya adalah pembuatan prototipe high fidelity, prototipe ini sudah membentuk sebuah aplikasi dengan konsep interaksi utuh aplikasi yang akan didapatkan oleh pengguna. Prototipe ini dibangun menggunakan database MySQL, framework codeigniter dan bootstrap.

Perancangan desain interface pada prototipe high fidelity menggunakan bahasa pemrograman PHP dengan database MYSQL. Framework yang digunakan adalah bootstrap dan codeigniter. Font yang digunakan adalah open sans dengan warna standar flat yang mengikuti standar dari situs flatuicolors. Warna utama aplikasi travary adalah warna orange dengan nilai HEX E67E22. Hasil prototipe high fidelity dapat dilihat pada Gambar 9.

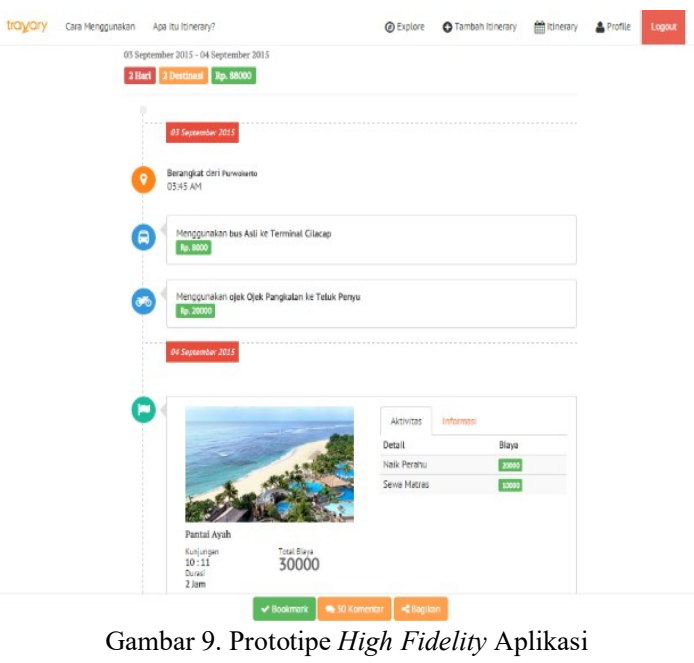

\subsection{Evaluasi}

Setelah dilakukan implementasi prototipe high fidelity dilakukan evaluasi menggunakan kuisioner online untuk mengevaluasi aplikasi tersebut. Kuisioner online dibagikan ke group media sosial wisatawan dengan total 20 responden. Responden diberikan kesempatan untuk mencoba dahulu aplikasi sebelum mengisi kuisioner. Pertanyaan kuisioner yang dibagi menjadi 2 bagian yaitu evaluasi UX untuk interface aplikasi dan kepentingan informasi dari aplikasi.

Pada kuisioner bagian pertama secara keseluruhan pembuatan desain interaksi aplikasi telah memenuhi kebutuhan informasi backpacker dalam merencanakan perjalanannya. Responden didominasi menyarankan perbaikan desain interaksi pada aplikasi yaitu mudah digunakan pada semua platform serta kemudahan akses informasi biaya masuk destinasi.

Pada kuisioner bagian kedua, responden memilih beberapa kepentingan penggunaan aplikasi yang sangat diperlukan. Penghitungan kuisioner kepentingan menggunakan skala likert yang dapat dilihat pada Tabel 2.

Sehingga dapat dilihat pada Tabel 2, bahwa kepentingan tiga fitur utama yang diinginkan pengguna berdasarkan nilai kepentingan tertinggi adalah kemudahan mengetahui informasi total biaya keseluruhan perjalanan wisata, mudah mengetahui informasi biaya transportasi, dan kemudahan informasi biaya pada destinasi.

Tabel 2. Pengurutan Kepentingan Berdasarkan Nilai Skala Likert

\begin{tabular}{lll}
\hline No & Pertanyaan & $\begin{array}{l}\text { Nilai } \\
\text { Kepentingan }\end{array}$ \\
\hline 1 & $\begin{array}{l}\text { Kemudahan Mengetahui Informasi } \\
\text { Total Biaya Keseluruhan Perjalanan } \\
\text { Wisata }\end{array}$ & 85 \\
2 & $\begin{array}{l}\text { Mudah Mengetahui Informasi Biaya } \\
\text { Transportasi }\end{array}$ & 84 \\
\hline
\end{tabular}




\begin{tabular}{|c|c|c|}
\hline No & Pertanyaan & $\begin{array}{l}\text { Nilai } \\
\text { Kepentingan }\end{array}$ \\
\hline 3 & $\begin{array}{l}\text { Kemudahan Mendapatkan } \\
\text { Informasi Biaya Pada Destinasi }\end{array}$ & 84 \\
\hline 4 & $\begin{array}{l}\text { Mudah Mengetahui Informasi } \\
\text { Durasi Transportasi Perjalanan }\end{array}$ & 83 \\
\hline 5 & $\begin{array}{l}\text { Mudah Mengetahui Pilihan } \\
\text { Alternatif Transportasi }\end{array}$ & 83 \\
\hline 6 & $\begin{array}{l}\text { Mudah Membaca Rute Transportasi } \\
\text { Menuju Destinasi }\end{array}$ & 83 \\
\hline 7 & $\begin{array}{l}\text { Mudah Membagikan Informasi } \\
\text { Itinerary Kepada Pengguna Lain }\end{array}$ & 83 \\
\hline 8 & $\begin{array}{l}\text { Mudah Melakukan Filter Informasi } \\
\text { Itinerary }\end{array}$ & 82 \\
\hline 9 & $\begin{array}{l}\text { Kemudahan Akses Review } \\
\text { Informasi Pada Destinasi }\end{array}$ & 82 \\
\hline 10 & $\begin{array}{l}\text { Secara menyeluruh, situs ini dapat } \\
\text { membantu saya dalam } \\
\text { merencanakan perjalanan wisata } \\
\text { Kemudahan Mengetahui Informasi }\end{array}$ & 82 \\
\hline 11 & $\begin{array}{l}\text { Aktifitas/Kegiatan Selama di } \\
\text { Destinasi }\end{array}$ & 81 \\
\hline 12 & Dapat dipelajari dengan mudah & 81 \\
\hline 13 & $\begin{array}{l}\text { Saya bisa menggunakannya tanpa } \\
\text { bimbingan orang lain }\end{array}$ & 81 \\
\hline 14 & $\begin{array}{l}\text { Foto Destinasi Membantu } \\
\text { Mengambarkan Kondisi Destinasi }\end{array}$ & 80 \\
\hline 15 & $\begin{array}{l}\text { Kemudahan Akses Informasi Biaya } \\
\text { Masuk Destinasi }\end{array}$ & 80 \\
\hline 16 & $\begin{array}{l}\text { Kemudahan Mengetahui Informasi } \\
\text { Biaya Aktifitas di Destinasi }\end{array}$ & 80 \\
\hline 17 & $\begin{array}{l}\text { Secara menyeluruh, saya suka } \\
\text { dengan tampilan ini dan akan } \\
\text { kembali menggunakan situs ini }\end{array}$ & 80 \\
\hline 18 & $\begin{array}{l}\text { Saya dapat menggunakan website } \\
\text { ini tanpa harus mempelajari hal } \\
\text { yang baru }\end{array}$ & 80 \\
\hline 19 & $\begin{array}{l}\text { Pattern Destinasi Tujuan Mudah } \\
\text { Dipahami }\end{array}$ & 79 \\
\hline 20 & $\begin{array}{l}\text { Dalam benak saya, orang lain pun } \\
\text { dapat mempelajari website ini } \\
\text { dengan cepat }\end{array}$ & 79 \\
\hline 21 & $\begin{array}{l}\text { Mudah Digunakan Pada Semua } \\
\text { Platform }\end{array}$ & 78 \\
\hline 22 & Fitur-fitur berjalan dengan baik & 76 \\
\hline 23 & $\begin{array}{l}\text { Mudah Bertanya Kepada Pengguna } \\
\text { Lain }\end{array}$ & 75 \\
\hline
\end{tabular}

\section{KESIMPULAN}

Berdasarkan penelitian yang telah dilakukan, maka dapat diambil kesimpulan bahwa penelitian ini berhasil menggunakan metode user experience lifecycle dalam mengembangkan aplikasi itinerary perjalanan wisata berbasis web. Hasil evaluasi menunjukan bahwa aplikasi sudah memenuhi kebutuhan informasi dalam penyusunan itinerary. Namun, interface aplikasi belum mudah untuk mencari informasi biaya masuk destinasi serta diakses semua platform. Selain itu kepentingan pengguna dalam menggunakan aplikasi lebih cenderung untuk mengetahui biaya perjalanan wisata.

\section{DAFTAR PUSTAKA}

ADINUGROHO, S. 2010. Menyusun Rencana Perjalanan. $14 \quad$ Juli 2019. http://ranselkecil.com/rencana/menyusunrencana-perjalanan/
CHANDLER, UNGER. 2012. A Project Guide to UX Design, Second Edition. Barkeley: New Riders.

HESSENZAHL, MARC. 2011. User Experience and Experience Design.

HUSNIA, ARINA. 2014. How to Make Itinerary. 14 April 2014. http://www.travelmatekamu.com/2014/04/1 4/how-to-make-itinerary/

International Organization for Standardization (ISO). 2010. Ergonomics of Human-System Interaction, 9241-210.

JUZMA, EK. 2019. Perancangan User Experience Pelatihan dan Evaluasi Trainer Menggunakan Metode The Wheel.

NADHIRAH, ASD. 2014. Perancangan Mobile User Experience Aplikasi Visit Puncak Untuk Perkiraan Kunjungan Wisatawan Kawasan Puncak Kabupaten Bogor.

PYLA, HARTSON. 2012. The UX Book Process and Guidelines for Ensuring a Quality User Experience. Waltham: Morgan Kaufmann.

SIHMANTO. 2010. Rp 2 Jutaan Keliling Vietnam dalam 15 Hari. Yogyakarta: B-First.

SPURLOCK, JAKE. 2013. Bootstrap. Sebastopol: O'Reilly Media Inc.

TRAVELSINGAPURA. 2012. Contoh Itinerary Wisata di Singapura. 21 Juli 2019. http://www.travelsingapura.com/contohitinerary-singapura/

WARDHANA, A. C., \& FITRIANA, G. F. (2021). Perancangan aplikasi pengukuran tingkat kesiapan inovasi menggunakan user experience lifecycle. Teknologi: Jurnal Ilmiah Sistem Informasi, 11(1), 34-45. 